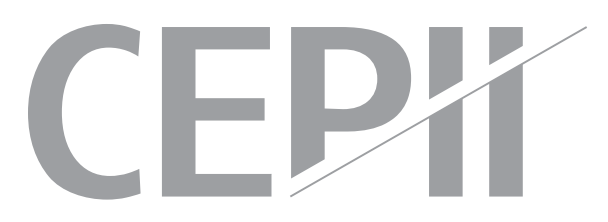

\title{
Exporting Creative and Cultural Products: Birthplace Diversity Matters!
}

\author{
Gianluca Orefice \& Gianluca Santoni
}

\section{Highlights}

- This paper analyses the role of diversity in the birthplaces of foreign-born individuals in trade in creative and cultural goods.

- A $10 \%$ increase in the diversity of immigrants (or a reduction in their concentration) increases creative goods exports by $4 \%$.

- The biggest contribution to the "creative" process in the creative and cultural goods industry is generated by birthplace diversity of tertiary educated immigrants. 


\section{Abstract}

This paper analyses the effect of birthplace diversity on exports of creative and cultural goods, for 19 OECD countries, over the period 1990-2010. By matching UNESCO's creative and cultural exports classification to trade and migration data, we find a strong positive effect of birthplace diversity on the export of creative products. In particular, a 10\% increase in the birthplace diversity index implies a $4 \%$ increase in creative goods export. These results are robust across several specifications and shed light on a potential new channel through which migrants can contribute to the host country's export performance. It is interesting to note that only diversity of secondary and tertiary educated immigrants contributes to an increase in exports of creative and cultural goods. An instrumental variables approach addresses the potential endogeneity problems and confirms our results.

\section{Keywords}

Creative Products, International Trade, Birthplace Diversity, Migration.

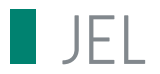

$\mathrm{F} 14, \mathrm{~F} 16, \mathrm{~F} 22$.

\section{Working Paper}

\section{CEPI}

CEPII (Centre d'Etudes Prospectives et d'Informations Internationales) is a French institute dedicated to producing independent, policyoriented economic research helpful to understand the international economic environment and challenges in the areas of trade policy, competitiveness, macroeconomics, international finance and growth.
CEPII Working Paper

Contributing to research in international economics

(c) CEPII, PARIS, 2017

All rights reserved. Opinions expressed in this publication are those of the author(s) alone.

$\begin{array}{ll}\text { Editorial Director: } & \text { CEPII } \\ \text { Sébastien Jean } & 113, \text { rue de Grenelle } \\ & 75007 \text { Paris } \\ \text { Production: } & +33153685500 \\ \text { Laure Boivin } & \\ \text { No ISSN: } 1293-2574 & \text { Prw.cepii.fr }\end{array}$




\title{
Exporting Creative and Cultural Products: Birthplace Diversity Matters! ${ }^{1}$
}

\author{
Gianluca Orefice (CEPII)* \\ Gianluca Santoni (CEPII) ${ }^{\dagger}$
}

\section{Introduction}

By showing that birthplace diversity has a positive and significant effect on the economic prosperity (per capita GDP) of host countries, the work of Alesina et al. (2016) triggered renewed interest from scholars in understanding the economic consequences of cultural diversity. The present paper, which is in the spirit of Alesina et al. (2016), analyses the effect of birthplace diversity on a specific component of rich countries' economic development: the exports of cultural and creative products.

In many developed countries, the cultural and creative industries account for an important share of total GDP and employment. According to a recent report by Tera Consulting (2014), in 2011 creative and cultural industries (core and non-core) ${ }^{2}$ represented $6.8 \%$ of total GDP and $6.5 \%$ of total employment in Europe. A closer look at specific EU members reveals that, for some countries, the creative and cultural industries are even more important. For example, in 2011, the UK creative and cultural industries accounted for $9 \%$ of total GDP and employment. Similarly, in France, these industries accounted for $7.9 \%$ of total GDP and $6.3 \%$ of total employment in 2011 . Thus, the creative and cultural industries play a crucial role in the economic development of wealthy countries. This is reflected in the pattern of increasing exports of creative and cultural products since the mid 1990s by the OECD countries. Figure 1 depicts total exports of creative goods for the sample of 19 OECD countries analysed in this paper and shows a clear positive pattern over time. Therefore,

\footnotetext{
${ }^{1}$ We thank Farid Toubal and Massimiliano Bratti for comments and suggestions. However, the views expressed in this article are those of the authors and also do not reflect those of the CEPII.

*113 rue de Grenelle - 75007 Paris (gianluca.orefice@cepii.fr)

${ }^{\dagger} 113$ rue de Grenelle - 75007 Paris (gianluca.santoni@cepii.fr)

${ }^{2}$ See Tera Consulting (2014) for a detailed definition of core and non-core creative and cultural industries: http://www.teraconsultants.fr/medias/uploads/pdf/Publications/2014/ 2014-Oct-European-Creative-Industry-GDP-Jobs-full-Report-ENG.pdf. In the present paper we adopt the UNESCO creative products classification. See Section 3.2 for a detailed description.
} 
understanding the determinants of creative and cultural goods exports should be of prime interest to policy makers in developed countries.

This paper analyses the role of diversity in the birthplaces of foreign-born individuals in trade in creative and cultural goods. ${ }^{3}$ People originating from different countries bring to their destination countries diverse skills, culture, value systems and problem-solving capabilities; which are crucial assets in the industry of creative and cultural goods. So, as suggested by Florida (2002), the implication for destination countries of diversity in the birthplace of immigrants is a more diverse distribution of worker types, and thus the presence of very talented workers and the burgeoning (or strengthening) of their innovative and creative industries. ${ }^{4}$ More formally, Lazear (1999) proposes a model in which the cost of diversity in production teams (i.e. coordination costs) might be over-compensated by production complementarities: "Disjoint and relevant skills create an environment where the gains from complementarities can be significant". In the same vein, Hong and Page (2001) demonstrate, theoretically, that a team of cognitively diverse individuals with limited abilities may perform better than a group of highly able, cognitively homogeneous individuals. Moreover, Maggi and Grossman (2000) develop a model in which the distribution of worker types (i.e. concentration/diversification of abilities in the country) matters for that country's comparative advantage and export performance. In particular, countries with a more diverse population will export goods produced using technologies characterized by high substitutability among employees, in which case, the presence of highly-talented workers is extremely important. Creative products belong to this category. Since highly-talented workers are relatively more present in more diverse countries (i.e. fat-tailed distribution of capabilities), these countries have comparative advantage in exporting creative products. This is the idea underlying the empirical exercise conducted in the present paper.

Previous empirical evidence suggests a positive effect of diversity on the performance of groups of individuals. Hoogendoorn and van Praag (2012) set a randomized field experiment and find that more ethnically diverse teams show better performance than less diverse teams. In more diverse teams, the coordination costs resulting from this diversity are offset by the pool of available relevant knowledge (skills), which facilitates (mutual) learning within ethnically diverse teams. Kahane et al. (2013) analyse data on the ethnic composition of National Hockey League teams in the US and find that more diverse teams (with a high share

\footnotetext{
${ }^{3}$ We define immigrants as foreign-born individuals.

${ }^{4}$ The seminal paper by Florida (2002) advanced the hypothesis that the presence of creative professionals and bohemian occupations across US cities has a positive effect on innovative and high-technology industries.
} 
of European players) demonstrate better performance. According to Kahane et al. (2013) the "productivity" premium provided by diverse teams lies in the skill effect (selection of best foreign players) and the complementarity between native and foreign-born players' skills. ${ }^{5}$ See Horwitz and Horwitz (2007) for a meta-study of the effect of diversity on team performance. In addition, diversity has a positive effect of the productivity of cities and firms. Ottaviano and Peri (2006) find that a more multicultural urban environment increases the productivity of US-born citizens. Trax et al. (2015) use German establishment level data to analyse the micro and the macro level effects of diversity on productivity. The authors find that both the diverseness of foreign born workers and the spillover from regional diversification increase the productivity of plants.

By testing the effect of diversity on the export of creative goods, we contribute also to the long debate on the effect of migration on exports. The literature on the trade-migration nexus suggests a strong positive effect of immigrants on the export performance of host countries. Migrant communities' business and social networks promote the export activity of host countries by reducing information costs and boosting the diffusion of preferences (Rauch, 2001 and Head and Ries, 1998). Migrants, especially highly-skilled individuals, help domestic firms in overcoming the cultural barriers to trade (language, local tastes, etc.) and creating international business relationships (Combes et al., 2005; Herander and Saavedra, 2005; Rauch and Trindade, 2002).

We complement the broad literature on birthplace diversity and economic performance, and add a new channel to the trade-migration nexus literature. The present paper provides two main contributions. First, we uncover a new channel through which diversity can affect national prosperity, that is, by affecting exports of creative and cultural products. Second, we make progress in addressing the endogeneity of migrants by providing an adjusted version of the shift share instrumental variable proposed by Card (2001).

The rest of the paper is organized as follows. Section 2 discusses the index of birthplace concentration used in the paper. Section 3 presents our empirical strategy, the data used to conduct the empirical exercise and how we address the problem of endogeneity. Section 4 presents the results and Section 5 concludes the paper.

\footnotetext{
${ }^{5}$ Peri and Sparber (2009) provide empirical evidence of a productivity effect from the complementarity among immigrant and native workers.
} 


\section{Herfindahl-Hirschman index to measure the birthplace diversity}

The first step in our empirical exercise is to compute a measure of the diversity in migrants' birthplaces, for each destination (exporting) country at time $t$. The guiding principle here, is to choose a simple and widely used measure of concentration. For this reason, we rely on a standard Herfindahl-Hirschman $(\mathrm{HH})$ concentration index applied to the population of immigrants. The $\mathrm{HH}$ index is used widely in many economics field from industrial and urban economics, where it is used to measure the concentration of activities around cities, to development economics, where the $\mathrm{HH}$ index is used to measure income inequalities. The only caveat accompanying its use as a proxy for birthplace diversity is related to its interpretation. An increase in the $\mathrm{HH}$ index represents a decrease in birthplace diversity. In other words, application of the HH index to immigrants' birthplace can be interpreted as the probability that two randomly selected immigrants in a given country come from the same origin. Thus, our measure of birthplace diversity ( $B D$ index) is as follows:

$$
B D_{i t}=\sum_{j=1}^{J} s_{i j t}^{2}
$$

where $s_{i j t}$ is the share of immigrants originating from $j$ in the total population of immigrants residing in country $i$ at time $t$. The $B D$ index increases with the concentration of migrants' birthplaces in the country (it is equal to 1 if there is only one immigrant country of origin). Countries with a few dominant migrant communities will have high $B D$ index values. Conversely, countries with many immigrant communities of similar size will have small $B D$ index values. In our sample, Ireland is the country with most concentrated distribution of immigrants (this is not surprising since, in 2010, 52\% of immigrants residing in Ireland originated from the UK). In contrast, Denmark has the most diverse immigrant population (in Denmark the largest community of immigrants is from Turkey and accounts for $8 \%$ of the total immigrant population). Figure 2 depicts the Lorenz curve for three of the countries in our sample (Ireland, Denmark and Germany) to give an idea of differences across countries in the concentration of birthplace of immigrants.

Notice that our measure of birthplace diversity is similar to that adopted in Alesina et al. (2016) and Trax et al. (2015). These works use an index that directly measures diversity in the birthplace of immigrants (i.e. 1 minus the $\mathrm{HH}$ index). ${ }^{6}$ In our baseline regressions

\footnotetext{
${ }^{6}$ The birthplace diversity index for immigrants in Alesina et al. (2016) can be expressed as follows: $B D_{i t}=$
} 
we include the $\mathrm{HH}$ index as an inverse measure of diversity (see equation (1)), we provide robustness checks using the same birthplace diversity index as in Alesina et al. (2016) to show that our results are robust to a direct or indirect measure of birthplace diversity. ${ }^{7}$

\section{Empirical Strategy}

This section describes the empirical strategy used to test the effect of birthplace diversity of immigrants on the export of creative goods. We follow a reduced form empirical approach inspired by Alesina et al. (2016) with total exports of creative products (in log) as the main dependent variable. The estimated equation is as follows: ${ }^{8}$

$$
L n(y)_{i k t}=\beta_{1} L n\left(B D_{i t}\right)+\beta_{2} X_{i t}+\theta_{k t}+\theta_{i k}+\varepsilon_{i k t} .
$$

The subscripts $i, k$ and $t$ denote respectively exporting country, HS 2-digit sector and year. The dependent variable $y_{i k t}$ is the creative and cultural exports of country $i$, sector $s$, time t. In order to keep the zeros after the log transformation, we simply impose that the $\operatorname{Ln}(y)_{i k t}$ is equal to zero when $y_{i k t}$ is zero. Notice that the number of zeros in the data is greatly reduced $(0.42 \%)$ because we have country-sector specific data only for rich countries (not using bilateral trade data reduces concerns about zero trade flows). However, we also use a PPML estimation, as proposed by Silva and Tenreyro (2006), to control for possible heteroscedasticity in the trade data. In the PPML estimations, we use creative products exports in levels rather than in log.

The main explanatory variable is the log of the birthplace diversity index $B D_{i t}$ as defined in Section 2. The set of control variables $X_{i t}$ includes: (i) the log of total exports of country $i$ in sector $k$ to control for the overall export dynamics of the country-sector; (ii) the number of countries of origin for migrants residing in country $i$; (iii) the country's total population, to control for the size effect on exports (as in Alesina et al., 2016); and (iv) the share of natives in the country's total population. Including the share of natives in the total population is important since it controls for the size effect of migration. It allows us to disentangle size from the fractionalization (diversity) of immigrants in the destination country - as in Alesina

$1-\sum_{j=1}^{J} s_{i j t}^{2}$. See Alesina et al. (2016) equation (8).

${ }^{7}$ This choice implies caution in the interpretation of results since an increase in our $B D$ index represents a reduction in diversity.

${ }^{8}$ We adopt a log-log specification because it is standard in the empirical literature using gravity model for trade. It implies interpretation of regression coefficients directly as elasticities. 
et al. (2016) and Trax et al. (2015). Including the share of natives allows us to test whether there is any direct effect of the foreign-born population on the export of creative goods. If the theoretical discussion in the introduction holds, we expect a null coefficient for the share of natives. What matters for export performance in creative products is the diversity of cultures and not the total number of immigrants. ${ }^{9}$ In a robustness check, reported in the appendix, we include per capita GDP as an additional covariate to control for the exporting country's income level. ${ }^{10}$

Any sector specific shock affecting the export of creative products in a given year (i.e. productivity shock, sector-specific innovation, technological improvement etc.) is captured by the sector-year fixed effects, $\theta_{k t}$, included in all the estimations. The inclusion of countrysector fixed effects, $\theta_{i k}$, allows us to control for any country-sector specific variable affecting the export of creative goods (i.e. sector comparative advantage, average level of development of the country, average expenditure in research and development in a country, etc.). The inclusion of country-sector fixed effects implies that our results should be interpreted in deviations from the country-sector mean (within estimator). The dependent variable (export of creative products) is country-sector-year specific; our main explanatory variable is country-year specific. For this reason, standard errors are clustered by country-year in all the estimations.

\subsection{Endogeneity}

A potential issue that needs to be addressed is endogeneity. Omitted variables concerns are reduced in our case since we include country-sector fixed effects which capture all unobserved destination specific factors affecting the settlement of immigrants in the host countries (i.e. average income level, immigration policy and any country specific economic factor attracting immigrants). However, an unobserved country-year specific shock might contemporaneously affect the exports of creative goods and the settlement of immigrants across destinations. Moreover, reverse causality could produce biased Ordinary Least Squares (OLS) estimations if changes in the export of creative goods affect the demand for labour in the country and, in particular, demand for high-skilled (immigrant) workers. We address these endogeneity

\footnotetext{
${ }^{9}$ Immigrants from the same country have a homogeneous culture and, thus, can be assumed to have homogeneous ability. In this respect, they do not spread the distribution of worker abilities in the destination country.

${ }^{10}$ We consider it peculiar to include both population and per capita GDP in the same specification and, for this reason, we report the augmented specification including per capita GDP only in the appendix. However, our baseline results do not change. See Appendix Table A1.
} 
concerns by adopting an instrumental variable approach (Two Stage Least Squares - 2SLS).

Much of the migration literature adopts the shift share instrument à la Card (2001) to solve the problem of endogeneity in immigrant settlement. ${ }^{11}$ Unfortunately, in our framework, the total bilateral flows of immigrants used to build the shift-share instrument would be unlikely to be exogenous (since they can be assumed to be affected by destination-year specific export performance and labour demand). So, we introduce an alternative instrumental variable, in line with Card (2001), but based on the predicted supply-driven number of migrants in each destination (exporting) country $i$. Basically, we run a structural gravity model that predicts the bilateral stocks of migrants (taken from IAB) ${ }^{12}$ using: (i) destination-year fixed effects; (ii) origin-year fixed effects; (iii) a set of country-pair specific geographic variables (distance, common border, language and colonial past) - $G e o_{i j}$; (iv) the share of immigrants coming from a specific origin in 1980; and (v) its interaction with the total stock of migrants from a given country - $\ln (/ m m i)_{j t}{ }^{13}$. We use a PPML estimator to account for the many zeros in bilateral migration stocks and to estimate the following equation:

$$
I m m i_{i j t}=\gamma_{i t}+\gamma_{j t}+\beta_{1} G e o_{i j}+\beta_{2} S h I m m i_{i j, 1980}+\beta_{3} S h I m m i_{i j, 1980} * I n(I m m i)_{j t}+\mu_{i j t}
$$

where the destination-year fixed effects $\left(\gamma_{i t}\right)$ capture the pull factors of bilateral migration, the origin-year fixed effects $\left(\gamma_{j t}\right)$ account for the origin-year specific push-factors affecting the outflow of migrants, and the set of gravity type covariates control for the country-pair specific migration cost. The inclusion of the share of immigrants in $i$ coming from $j$ in 1980 $\left(S h / m m i_{i j, 1980}\right)$ and its interaction with $/ n(/ m m i)_{j t}$ mimics the idea in Card (2001) that new immigrants tend to settle in destinations where previous immigrants from the same origin already reside. The main advantage of this specification relies on the fact that $G e o_{i j}$ will contribute to predicting the bilateral stock of migrants also for those origin-destination pairs ij with zero migrants in the base year of $S h / m m i_{i j, 1980}$. From equation (3) we take the predicted value $\widehat{\mathrm{mmi}_{i j t}}$ (fit of the regression) from which we exclude the destination-year

\footnotetext{
${ }^{11}$ See for example Ottaviano and Peri (2006); Peri and Requena-Silvente (2010); Card (2009).

${ }^{12}$ See next section for more details of data sources.

${ }^{13}$ Note that the direct effect of $\ln (/ \mathrm{mmi})_{j t}$ is captured by $\gamma_{j t}$.
} 
fixed effect component:

$$
A \widehat{\operatorname{jlmm}} i_{i j t}=\widehat{\mathrm{mmi}_{i j t}}-\widehat{\gamma_{i t}} \text {. }
$$

Thus, our instrumental variable does not include the demand-driven component of bilateral migration, which is the origin of the endogeneity concern in our framework (and the basis for the main critiques of the shift-share instrument). Finally, we build the birthplace concentration index as in (eq.1) using $A \widehat{\operatorname{dj} \widehat{I m m} i_{i j t}}$ :

$$
V_{i t}=\sum_{j=1}^{J}\left(\frac{A d \widehat{j I m m} i_{i j t}}{\sum_{j=1}^{J} A \widehat{A d j I m m} i_{i j t}}\right)^{2}
$$

Notice that $\left(\frac{A d \widehat{j} / m m i i_{i j t}}{\left.\sum_{j=1}^{J} A d \bar{j} / m m i_{i j t}\right)}\right)$ is simply the share in the total population of the supply driven predicted number of migrants in country $i$ originating from country $j$. Thus, the BD index is built purely on the supply-driven migration component and can be used safely as an instrumental variable, $I V_{i t}$. The exclusion restriction assumption here is that this $B D$ index based on supply-driven migration stocks (i.e. $I V_{i t}$ ) affects the export of creative goods only through the $B D$ index based on total migration stocks. This is tested in Appendix Table A2 which shows that $I V_{i t}$ has no direct effect on the export of creative goods.

As a robustness check, we use the 5-year lag of the $B D$ index as an instrumental variable, which allows us to test an overidentified model and to apply a Sargan test for validity of the instrumental variables. The idea is that the composition of the migrant population is persistent over time, so the lagged value of the diversity index is a good proxy for the current diversity index value (relevant IV). Moreover, any contemporaneous shock to creative products exports cannot be related to previous values of the diversity index (IV validity).

\subsection{Data and Descriptive evidence}

Our calculation of the $\mathrm{BD}$ index relies on IAB bilateral migration stocks data. IAB data include information on migrants' country of origin (nationality) and education level for 20 OECD destination countries, during the period 1980-2010 (5-year intervals). Data on the education level of immigrants (primary, secondary, tertiary) allow us to test the effect of birthplace diversity by skill level. ${ }^{14}$ To calculate the concentration index, we consider migrants

\footnotetext{
${ }^{14}$ Dataset available here: http://www.iab.de/en/daten/iab-brain-drain-data.aspx.
} 
as foreign-born individuals aged at least 25 years. A potential drawback of using IAB data is that they report only the nationalities. Naturalized foreign-born individuals and second generation immigrants are not classified as "immigrant" in our data. So, our measure of birthplace concentration underestimates the real degree of cultural diversity.

As a robustness check, we use bilateral migration flows rather than stocks to compute the concentration index. In this case, we rely on the data in Abel and Sander (2014), which provide information on bilateral migration flows for a $178 * 178$ matrix of origin-destination combinations, for the years 1995, 2000, 2005 and 2010. ${ }^{15}$ Bilateral migration stocks (and flows) are used to compute a country-year specific birthplace diversity measure (see eq. 1 ) that can be merged with data on creative and cultural goods exports.

In order to calculate the volume of creative and cultural goods exports, we combine trade data from BACI (CEPII) with three recent HS-based classifications of creative and cultural goods. The first classification was released by UNESCO and includes only the core creative industries (used here as baseline). The second was also released by UNESCO and includes both core and non-core creative industries (robustness check). The third classification used in this paper was released by UNCTAD (robustness check). Trade data from BACI provide information on the value of export flows (in USD) for a complete set of exporting and importing countries in the period 1989-2015, by product HS 6-digit level. Then, the UNESCO (and UNCTAD) classification is used to identify whether a specific HS 6-digit code belongs to the category "creative and cultural exports". This allows us to compute the total amounts of creative and cultural goods exports by country-sector(HS2)-year, which we use as the main dependent variable in our empirical exercise. Notice that, in our regression sample, we include only the HS 2-digit sectors containing at least one HS 6-digit product classified as "creative or cultural".

Merging trade data on cultural products (UNESCO core classification) with the BD index based on the stock of migrants (baseline estimations), produces a sample of 1,425 observations: 19 exporting countries, ${ }^{16} 15$ HS 2-digit sectors, and 5 years (1990, 1995, 2000, 2005 and 2010). See Table 1 panel A for in-sample descriptive statistics. When we use the UNESCO (core plus non-core) classification, the number of observations increases slightly (1,615 observations) because two additional HS 2-digit sectors include non-core creative

\footnotetext{
${ }^{15}$ This dataset is available at: http://science.sciencemag.org/content/sci/suppl/2014/03/27/343. 6178.1520.DC1/Abel-Database-s2.xlsx. The main advantage of this dataset, with respect to other sources (e.g. IMD-OECD), is the balanced nature of the data which include all other non-OECD destination countries. ${ }^{16}$ Luxembourg is not included due to numberous missing observations in the trade data.
} 
products (see Table 1 panel B). When we use the UNCTAD classification for creative goods, the number of observations increases because it includes 29 HS 2-digit chapters with creative products. See Table 1 panel $C$ for in-sample descriptive statistics using the UNCTAD classification to define creative products. Importantly, our results are robust to the three classifications used to define creative exports. In contrast, if we merge trade data with the BD index based on flows of migrants (robustness check), the number of observations increases since the sample of exporting countries is larger (178 exporting countries).

Figure 3 depicts the simple correlations between countries' exports of creative products (country averages across sectors), conditioned on the size of the country, and the diversity of immigrants' birthplaces (HH index). For the years 1995, 2000, 2005 and 2010 the relation is always negative, suggesting a positive correlation between the export of creative products and diversity in immigrants' birthplaces.

\section{Results}

\subsection{Baseline Results}

OLS results for equation 2 are presented in Table 2. Across all specifications, the concentration of immigrant birthplaces has a negative and significant effect on the export of creative and cultural goods. This means that immigrant diversity has a positive impact on the creative goods exports. In particular, using our preferred specification (column 3), a 10\% decrease in the birthplace concentration index implies a $4 \%$ boost in the export of creative and cultural goods. Notice that our results hold for both the UNESCO and the UNCTAD classifications of creative and cultural goods (see columns 3-5). As expected, the share of natives in the total population has no effect on the export of creative products, confirming the idea that it is the diversity in immigrants' origins that matters for the export of creative goods, not the size of the foreign-born population. Our baseline results are robust to the inclusion of per capita GDP among the covariates. See Appendix Table A1.

Table 3 presents the results of the 2SLS using the instrumental variables described in Section 3.1. Column 1 presents the estimation results using the IV based on the predicted supplydriven migration stocks and, column 2 presents the results using a 5-year lag of the BD index as an instrumental variable. In columns 3-5 we employ an overidentified model and put both IVs in the first stage. The relevance of the two IVs is suggested by the first stage coefficients at the bottom of the table. In all the specifications, the instruments are good proxies for the 
(potential) endogenous BD index. The first stage F-stat are all considerably above the rule of thumb value of 10 and remove any potential problem of weak instruments. The Sargan tests presented in columns 3-5 prove the validity of our IVs (orthogonality). Finally, in order to support the exclusion restriction of our IVs (as suggested by Conley et al., 2012), we estimate equation (2) by adding the two IVs (separately, and then together) as additional covariates to test whether they have a direct effect on the export of creative goods. The exclusion restriction assumption is satisfied if the IVs affect the export of creative goods only through their influence on the endogenous regressor (and, thus, when they have no direct effect on the export of creative goods). As expected, none of the IVs has a significant direct effect on the export of creative goods, supporting the validity of the exclusion restriction (see Table A2). The second stage results of the 2SLS approach are reported at the top of Table 3 and confirm what discussed above. Diversity in the birthplace of immigrants has a positive and significant effect on the export of creative goods (no matter which classification is used to identify creative products). In particular, a 10\% decrease in the BD index (i.e. an increase in birthplace diversity), implies a $4.4 \%$ increase in the export of creative products see column 3 in Table 3.

Table 4 presents our first robustness check using a PPML estimator to address the zero trade flow problem. Our results perfectly hold when we use the UNESCO classification (both core, and core plus-non-core classifications) - see columns 1 and 2 . The sign of the coefficient is in line with expectations for the UNCTAD classification also, but is estimated with errors (coefficient not significantly different from zero).

Table 5 presents another robustness check using the alternative definition of birthplace diversity proposed by Alesina et al. (2016) - one minus the HH index applied to the population of immigrants. The results are qualitatively similar to those obtained using our $B D$ index, but have the opposite signs (the measure proposed by Alesina et al. (2016) is a direct measure of diversity). Appendix Table A3 presents the 2SLS results using the birthplace diversity index, as in Alesina et al. (2016). As in our baseline estimations, we use two instrumental variables: (i) the diversity index $(1-\mathrm{HH})$ based on the supply driven predicted migration stocks, and (ii) a five-year lag of the diversity index $(1-\mathrm{HH})$. In all the specifications (for the three classifications of creative goods), an increase in birthplace diversity index boosts the export of creative goods. ${ }^{17}$ To support the validity of our results, in table A5 we report a placebo

\footnotetext{
${ }^{17}$ One issue with the econometric strategy adopted in the paper is the fact that total exports (control variable) indeed includes also the dependent variable. This is a reduced concerns because for many country-sectors the share of creative over total exports is less than $5 \%$ (the empirical distribution of the share of creative product
} 
test showing the effect of birthplace diversity on non-creative products. As expected, the diversity in the birthplace of immigrants does not play any role on the export of non creative products. This is true for both our measure of diversity and for the one adopted in Alesina et al. (2016). ${ }^{18}$

\subsection{Robustness check using migration flows}

The main drawback to IAB data on bilateral migration stocks is the small sample of destination countries (19 OECD countries), which implies the validity of the diversity-creative export nexus for the sub-sample of rich countries only. In this section, we account for this limitation by increasing the set of destination (exporting) countries using Abel and Sander (2014) data on bilateral migration flows to/from 178 countries. The construction of the $B D$ index does not change; we simply apply equation (1) to an alternative migration dataset including a bigger sample of destination countries.

The results of this robustness check are reported in Table 6 and show that, even if we consider a bigger set of exporting countries (both developed and developing), the positive effect of birthplace diversity on the export of creative goods holds, but the coefficient is smaller, indicating that the inclusion of poor countries weakens the nexus. This suggests that the effect of birthplace diversity for boosting exports of creative goods is particularly important for developed countries.

\subsection{Results by skill level}

As discussed in the introduction, the diversity and export of creative goods nexus is supposed to be particularly strong for the most talented workers (see Florida, 2002). The biggest contribution to the "creative" process in the creative and cultural goods industry is supposed to be generated by tertiary educated individuals. So, we expect diversity among high-skilled immigrants to have the strongest effect on the export of creative goods. We exploit information on immigrants' education level from IAB and compute the $B D$ index (as in eq.1) by education level. The baseline specification results by education level are reported in Table 7 . We find negative and significant coefficient for the concentration of tertiary and secondary educated migrants, confirming the intuition that what matters for the export of creative

exports has median equal to $5 \%$ ). To address this residual concern, in table A4, we provide an additional robustness check using the share of creative in all products on the left-hand side and results hold.

${ }^{18}$ Two specifications show a very weak coefficient on birthplace diversity with, however, a counterintuitive positive sign. 
goods is the diversity in the group of the most talented workers. Moreover, in line with the intuition, the coefficient of tertiary educated is bigger than the coefficient of secondary educated immigrants.

\subsection{Results by macro-sector}

Finally, Table 8 reports the baseline estimation results by macro-sector. Diversity in immigrants' birthplaces may be of particular interest for some sectors and less relevant for others. While the estimated specification does not change (see eq. 2), we needed to adapt the set of fixed effects included in the regression to achieve sufficient variability in the data to identify the coefficient of interest. Therefore, we include only country and year fixed effects in the sector specific regressions. Interestingly, the strongest contribution of birthplace diversity in boosting the export of creative goods is in: (i) Plastic and Rubbers, (ii) Wood and Wood products and (iii) Miscellaneous. Notice that the Miscellaneous macro-sector includes HS chapters 90 to 97 , that is, optical, photographic and cinematographic products, clocks and watches, musical instruments, toys and games, works of art.

\section{Conclusion}

This paper has proposed a new channel through which diversity in the birthplaces of immigrants can affect the economic performance of the host country. We used a sample of 19 OECD developed countries over the period 1995-2010 and found overwhelming evidence of a positive effect of immigrants' birthplace diversity on the export of creative and cultural products. This holds in particular for highly skilled and medium-skilled immigrants.

More specifically, according to our preferred specification, a $10 \%$ increase in the diversity of immigrants (or a reduction in their concentration) increases creative goods exports by $4 \%$. This result, along with the important role of the creative and cultural goods industry in developed countries, suggests the policy relevance of our paper. Attracting immigrants from a more diverse set of origin countries may be a way to boost exports of creative and cultural products, which are important for the economic prosperity of developed countries. 


\section{Tables and Figures}

Figure 1 - Exports of creative goods and $\mathrm{HH}$ index of immigrants' birthplace: OECD countries, 1990-2010

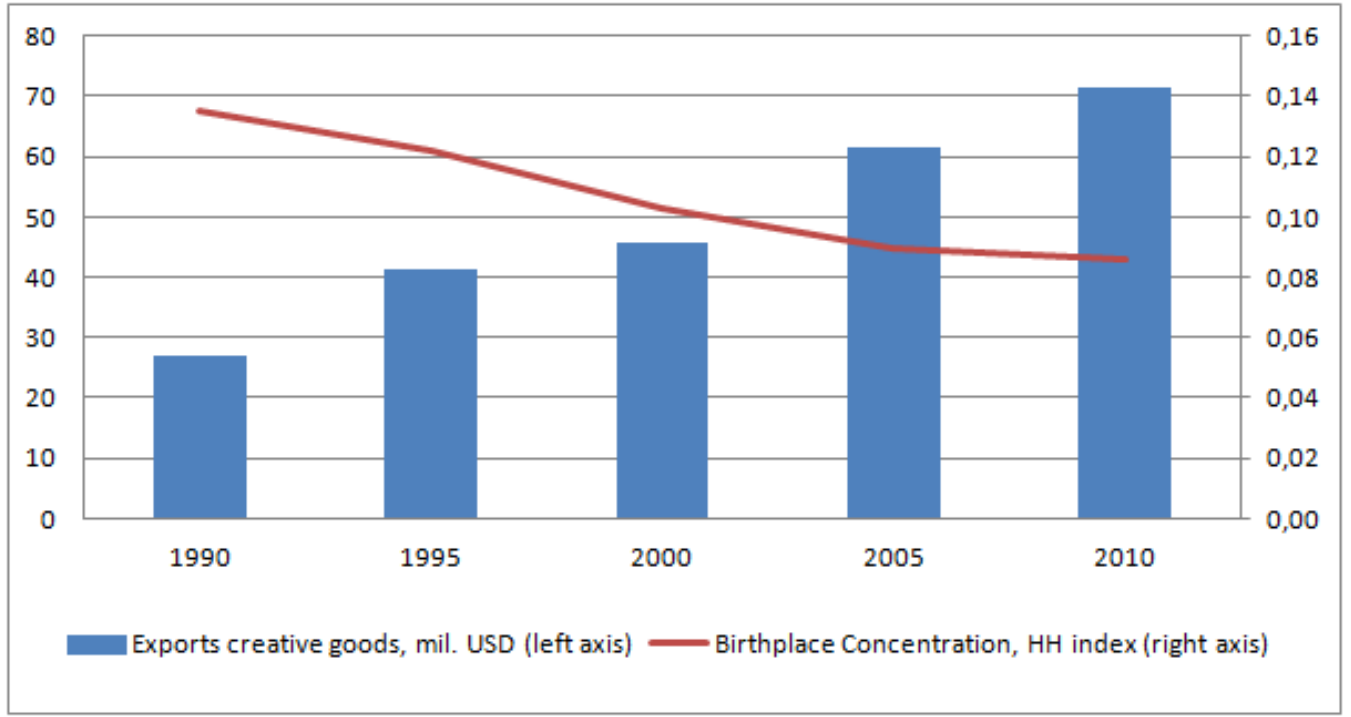

Note: The blue bars report the total amount of exports in cultural and creative goods for the full sample of exporting countries in our data. The red line refers to the average HH index of immigrants' birthplace across exporting countries. Source: Authors' calculation on BACI and IAB data. 
Figure 2 - Concentration of immigrant birthplaces in Ireland, Germany and Denmark in 2010: Lorenz curves

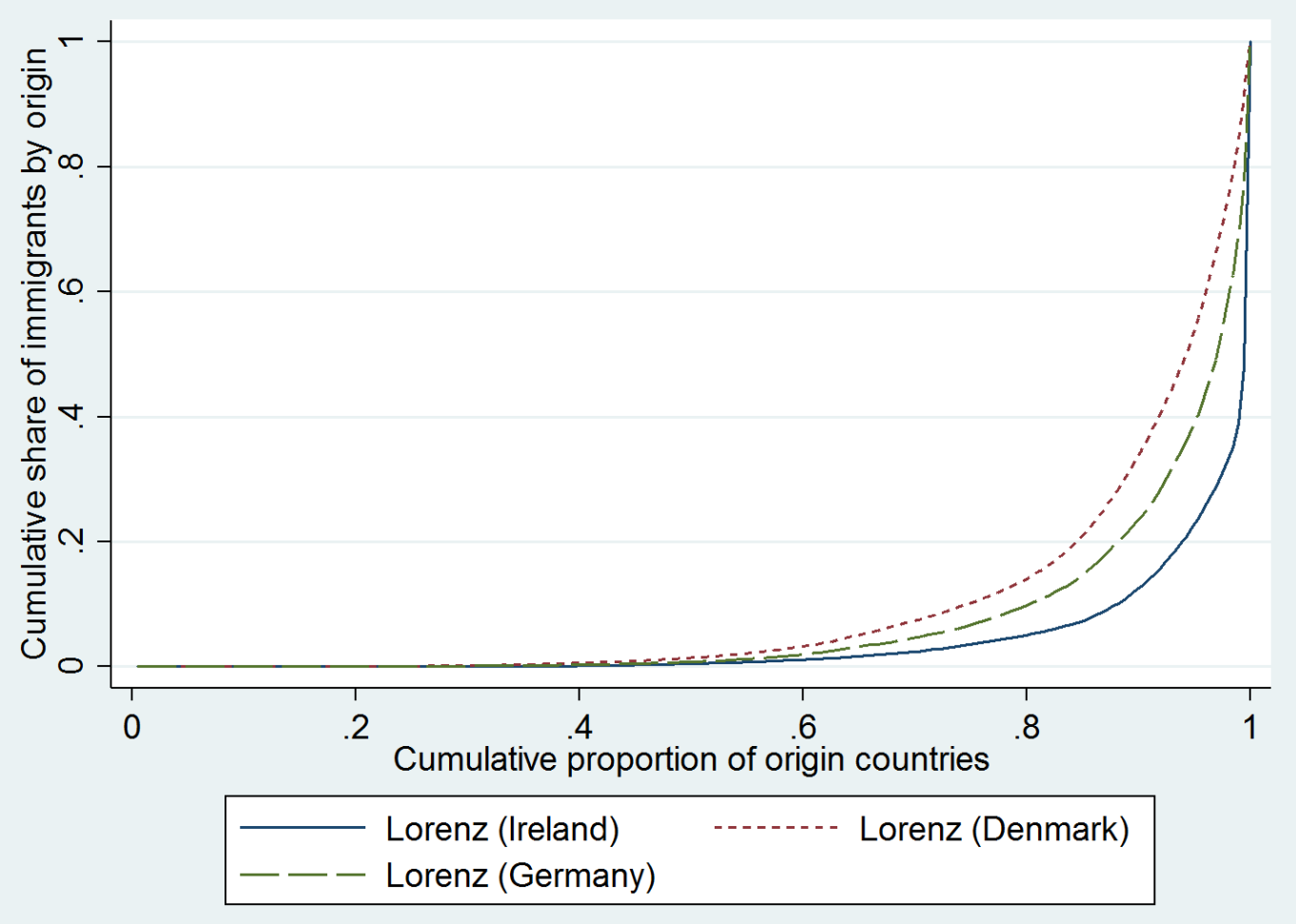

Source: Authors' calculation on IAB data. 


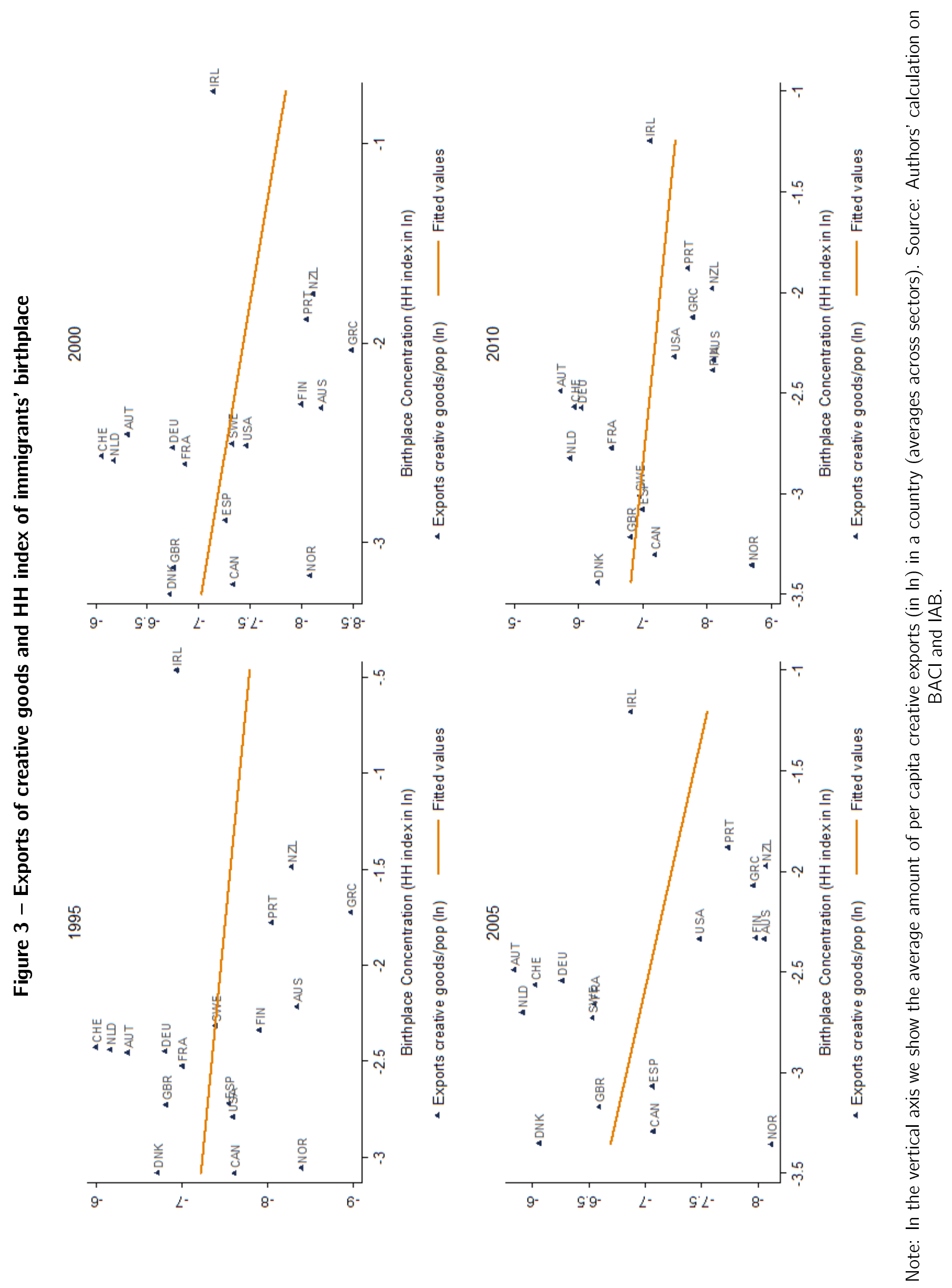


Table 1 - In-sample descriptive statistics: Estimation samples based respectively on UNESCO core, UNESCO and UNCTAD classification

\begin{tabular}{lccc}
\hline & Obs & Mean & Std Dev \\
\hline Panel A & \multicolumn{2}{c}{ UNESCO core } & classification \\
\hline Exports creative $(\log )$ & 1425 & 9.01 & 2.91 \\
Birthplace Diversity $(\log$ of HH) & 1425 & -2.46 & 0.60 \\
Tot exports $(\log )$ & 1425 & 12.25 & 2.37 \\
Population $(\log )$ & 1425 & 16.56 & 1.16 \\
Num. of origins & 1425 & 157.34 & 39.02 \\
Share of Natives & 1425 & 0.91 & 0.05 \\
\hline Panel B & \multicolumn{2}{c}{ UNESCO classification } \\
\hline Exports creative $(\log )$ & 1615 & 9.69 & 3.11 \\
Birthplace Diversity $(\log$ of HH) & 1615 & -2.46 & 0.60 \\
Tot exports (log) & 1615 & 12.58 & 2.51 \\
Population (log) & 1615 & 16.56 & 1.16 \\
Num. of origins & 1615 & 157.35 & 39.02 \\
Share of Natives & 1615 & 0.91 & 0.05 \\
\hline Panel C & \multicolumn{3}{c}{ UNCTAD classification } \\
\hline Exports creative $(\log )$ & 2755 & 9.25 & 2.70 \\
Birthplace Diversity $(\log$ of HH) & 2755 & -2.46 & 0.60 \\
Tot exports (log) & 2755 & 11.86 & 2.57 \\
Population (log) & 2755 & 16.57 & 1.16 \\
Num. of origins & 2755 & 157.35 & 39.02 \\
Share of Natives & 2755 & 0.91 & 0.05 \\
\hline
\end{tabular}


Table 2 - Birthplace diversity and creative products exports: Baseline results, OLS estimations

\begin{tabular}{lccc|cc}
\hline \hline & \multicolumn{5}{c}{ Exports of creative products (in log) } \\
\hline Birthplace Diversity (log of HH) & $-0.343^{* *}$ & $-0.392^{* * *}$ & $-0.392^{* * *}$ & $-0.284^{* *}$ & $-0.246^{* *}$ \\
& $(0.145)$ & $(0.133)$ & $(0.135)$ & $(0.111)$ & $(0.095)$ \\
Tot exports $(\mathrm{log})$ & $0.770^{* * *}$ & $0.766^{* * *}$ & $0.766^{* * *}$ & $0.839^{* * *}$ & $0.825^{* * *}$ \\
& $(0.061)$ & $(0.064)$ & $(0.064)$ & $(0.044)$ & $(0.047)$ \\
Population (log) & -1.154 & -1.110 & -1.112 & $-0.992^{*}$ & $-1.096^{* *}$ \\
& $(0.728)$ & $(0.697)$ & $(0.698)$ & $(0.588)$ & $(0.544)$ \\
Num. of origins & & -0.002 & -0.002 & $-0.002^{*}$ & -0.002 \\
& & $(0.002)$ & $(0.002)$ & $(0.001)$ & $(0.002)$ \\
Share of Natives & & & -0.022 & -1.231 & 0.137 \\
& & & $(2.121)$ & $(1.801)$ & $(1.475)$ \\
\hline Product Classification & UNESCO & UNESCO & UNESCO & UNESCO & UNCTAD \\
& Core & Core & Core & & \\
\hline Country-sector FE & yes & yes & yes & yes & yes \\
Sector-year FE & yes & yes & yes & yes & yes \\
\hline Observations & 1,425 & 1,425 & 1,425 & 1,615 & 2,755 \\
R-squared & 0.967 & 0.967 & 0.967 & 0.980 & 0.971 \\
\hline \hline
\end{tabular}

$\mathrm{HH}$ index is an inverse measure of diversity. A negative coefficient suggests a positive relationship between birthplace diversity and export of creative goods. Standard errors are clustered by country-year. $* * * p<0,01 ; * * p<0,05 ; * p<0,1$. 
Table 3 - Birthplace diversity and creative products exports: Baseline results, 2SLS estimations

\begin{tabular}{lccc|cc}
\hline \hline & \multicolumn{5}{c}{ Exports of creative products (in log) } \\
\hline & $(1)$ & $(2)$ & $(3)$ & $(4)$ & $(5)$ \\
\hline Birthplace Diversity (log of HH) & $-0.533^{* *}$ & $-0.397^{* *}$ & $-0.436^{* *}$ & $-0.379^{* *}$ & $-0.346^{* * *}$ \\
& $(0.256)$ & $(0.176)$ & $(0.171)$ & $(0.167)$ & $(0.128)$ \\
Tot exports (log) & $0.765^{* * *}$ & $0.766^{* * *}$ & $0.766^{* * *}$ & $0.837^{* * *}$ & $0.823^{* * *}$ \\
& $(0.064)$ & $(0.064)$ & $(0.064)$ & $(0.044)$ & $(0.048)$ \\
Population (log) & -1.133 & -1.113 & -1.118 & $-1.005^{*}$ & $-1.109^{*}$ \\
& $(0.701)$ & $(0.697)$ & $(0.697)$ & $(0.591)$ & $(0.560)$ \\
Num. of origins & -0.003 & -0.002 & -0.002 & $-0.003^{*}$ & -0.002 \\
& $(0.002)$ & $(0.002)$ & $(0.002)$ & $(0.001)$ & $(0.002)$ \\
Share of Natives & 0.342 & -0.010 & 0.090 & -0.987 & 0.394 \\
& $(2.219)$ & $(2.219)$ & $(2.203)$ & $(1.896)$ & $(1.551)$ \\
\hline Product Classification & UNESCO & UNESCO & UNESCO & UNESCO & UNCTAD \\
& Core & Core & Core & & \\
\hline Country-sector FE & yes & yes & yes & yes & yes \\
Sector-year FE & yes & yes & yes & yes & yes \\
\hline IV: BD based on imputed immigrants & $0.791^{* * *}$ & & $0.379^{* * *}$ & $0.379^{* * *}$ & $0.375^{* * *}$ \\
IV: 5-year lag BD & & $0.693^{* * *}$ & $0.550^{* * *}$ & $0.550^{* * *}$ & $0.549^{* * *}$ \\
F-test & 26.59 & 73.42 & 75.58 & 75.94 & 75.59 \\
Hansen J & & & 0.480 & 0.523 & 0.251 \\
\hline Observations & 1,425 & 1,425 & 1,425 & 1,615 & 2,755 \\
R-squared & 0.967 & 0.967 & 0.967 & 0.980 & 0.971 \\
\hline \hline
\end{tabular}

$\mathrm{HH}$ index is an inverse measure of diversity. A negative coefficient suggests a positive relationship between birthplace diversity and export of creative goods. Standard errors are clustered by country-year.

*** $p<0,01 ; * * p<0,05 ; * p<0,1$. 
Table 4 - Birthplace diversity and creative products exports: Robustness check using PPML estimation

\begin{tabular}{lccc}
\hline \hline & \multicolumn{3}{c}{ Exports of creative products } \\
\hline & $(1)$ & $(2)$ & $(3)$ \\
\hline Birthplace Diversity (log of $\mathrm{HH})$ & $-0.144^{* * *}$ & $-0.252^{* * *}$ & -0.018 \\
& $(0.046)$ & $(0.080)$ & $(0.031)$ \\
Tot exports (log) & $0.821^{* * *}$ & $1.085^{* * *}$ & $0.909^{* * *}$ \\
& $(0.055)$ & $(0.066)$ & $(0.031)$ \\
Population (log) & -0.341 & 0.063 & $-0.711^{* *}$ \\
& $(0.430)$ & $(0.790)$ & $(0.287)$ \\
Num. of origins & $-0.002^{* *}$ & 0.001 & $-0.001^{* * *}$ \\
& $(0.001)$ & $(0.001)$ & $(0.000)$ \\
Share of Natives & $-2.490^{*}$ & -1.291 & 0.239 \\
& $(1.512)$ & $(2.007)$ & $(0.932)$ \\
\hline Product Classification & UNESCO & UNESCO & UNCTAD \\
& Core & & \\
\hline Country-sector FE & yes & yes & yes \\
Sector-year FE & yes & yes & yes \\
\hline Observations & 1,425 & 1,615 & 2,755 \\
R-squared & 0.989 & 0.986 & 0.991 \\
\hline \hline
\end{tabular}

$\mathrm{HH}$ index is an inverse measure of diversity. A negative coefficient suggests a positive relationship between birthplace diversity and export of creative goods. Standard errors are clustered by country-year.

$* * * p<0,01 ; * * p<0,05 ; * p<0,1$.

Table 5 - Birthplace diversity and creative products exports. Robustness check using alternative definition of birthplace diversity, OLS estimations

\begin{tabular}{lccc|cc}
\hline \hline & \multicolumn{5}{c}{ Exports of creative products (in log) } \\
\hline Birthplace Diversity (1-HH) & $(1)$ & $(2)$ & $(3)$ & $(4)$ & $(5)$ \\
& $\left(0.846^{*}\right.$ & $2.477^{* * *}$ & $2.506^{* * *}$ & $1.774^{* * *}$ & $1.574^{* * *}$ \\
Tot exports (log) & $0.758^{* * *}$ & $0.739^{* * *}$ & $0.740^{* * *}$ & $0.820^{* * *}$ & $0.814^{* * *}$ \\
& $(0.062)$ & $(0.062)$ & $(0.061)$ & $(0.045)$ & $(0.042)$ \\
Population (log) & $-1.708^{* *}$ & $-2.034^{* * *}$ & $-2.011^{* * *}$ & $-1.623^{* *}$ & $-1.654^{* * *}$ \\
& $(0.770)$ & $(0.711)$ & $(0.709)$ & $(0.634)$ & $(0.534)$ \\
Num. of origins & & $-0.005^{* * *}$ & $-0.005^{* * *}$ & $-0.004^{* * *}$ & $-0.003^{* * *}$ \\
& & $(0.001)$ & $(0.001)$ & $(0.001)$ & $(0.001)$ \\
Share of Natives & & & 0.437 & -0.925 & 0.488 \\
& & & $(2.038)$ & $(1.692)$ & $(1.466)$ \\
\hline Product Classification & UNESCO & UNESCO & UNESCO & UNESCO & UNCTAD \\
& Core & Core & Core & & \\
\hline Country-sector FE & yes & yes & yes & yes & yes \\
Sector-year FE & yes & yes & yes & yes & yes \\
\hline Observations & 1,425 & 1,425 & 1,425 & 1,615 & 2,755 \\
R-squared & 0.967 & 0.968 & 0.968 & 0.981 & 0.971 \\
\hline \hline
\end{tabular}

Standard errors are clustered by country-year.

$* * * p<0,01 ; * * p<0,05 ; * p<0,1$. 
Table 6 - Birthplace diversity and creative products exports: Robustness check using migration flows, OLS estimations

\begin{tabular}{lcccc|cc}
\hline \hline & \multicolumn{7}{c}{ Exports of creative products (in log) } \\
\hline & $(1)$ & $(2)$ & $(3)$ & $(4)$ & $(5)$ & $(6)$ \\
\hline Birthplace Diversity (log of HH) & $-0.080^{* *}$ & $-0.092^{* *}$ & $-0.092^{* *}$ & $-0.109^{* * *}$ & $-0.089^{* *}$ & $-0.081^{* *}$ \\
& $(0.035)$ & $(0.041)$ & $(0.041)$ & $(0.042)$ & $(0.036)$ & $(0.033)$ \\
Tot exports (log) & $0.455^{* * *}$ & $0.455^{* * *}$ & $0.455^{* * *}$ & $0.456^{* * *}$ & $0.542^{* * *}$ & $0.520^{* * *}$ \\
& $(0.020)$ & $(0.020)$ & $(0.020)$ & $(0.020)$ & $(0.018)$ & $(0.016)$ \\
Population (log) & -0.298 & -0.304 & -0.304 & $-0.569^{* *}$ & $-0.431^{*}$ & -0.207 \\
& $(0.337)$ & $(0.345)$ & $(0.345)$ & $(0.277)$ & $(0.251)$ & $(0.229)$ \\
Num. of origins & & -0.000 & -0.000 & -0.002 & -0.001 & -0.001 \\
& & $(0.001)$ & $(0.001)$ & $(0.001)$ & $(0.001)$ & $(0.001)$ \\
Share of Natives & & & & $-1.952^{* *}$ & -0.968 & $-1.408^{* *}$ \\
& & & & $(0.897)$ & $(0.828)$ & $(0.701)$ \\
\hline Product Classification & UNESCO & UNESCO & UNESCO & UNESCO & UNESCO & UNCTAD \\
& Core & Core & Core & Core & & \\
\hline Country-sector FE & yes & yes & yes & yes & yes & yes \\
Sector-year FE & yes & yes & yes & yes & yes & yes \\
\hline Observations & 9,608 & 9,608 & 9,608 & 9,608 & 11,764 & 20,068 \\
R-squared & 0.943 & 0.943 & 0.943 & 0.943 & 0.954 & 0.954 \\
\hline \hline
\end{tabular}

$\mathrm{HH}$ index is an inverse measure of diversity. A negative coefficient suggests a positive relationship between birthplace diversity and export of creative goods. Standard errors are clustered by country-year.

*** $p<0,01 ; * * p<0,05 ; * p<0,1$. 


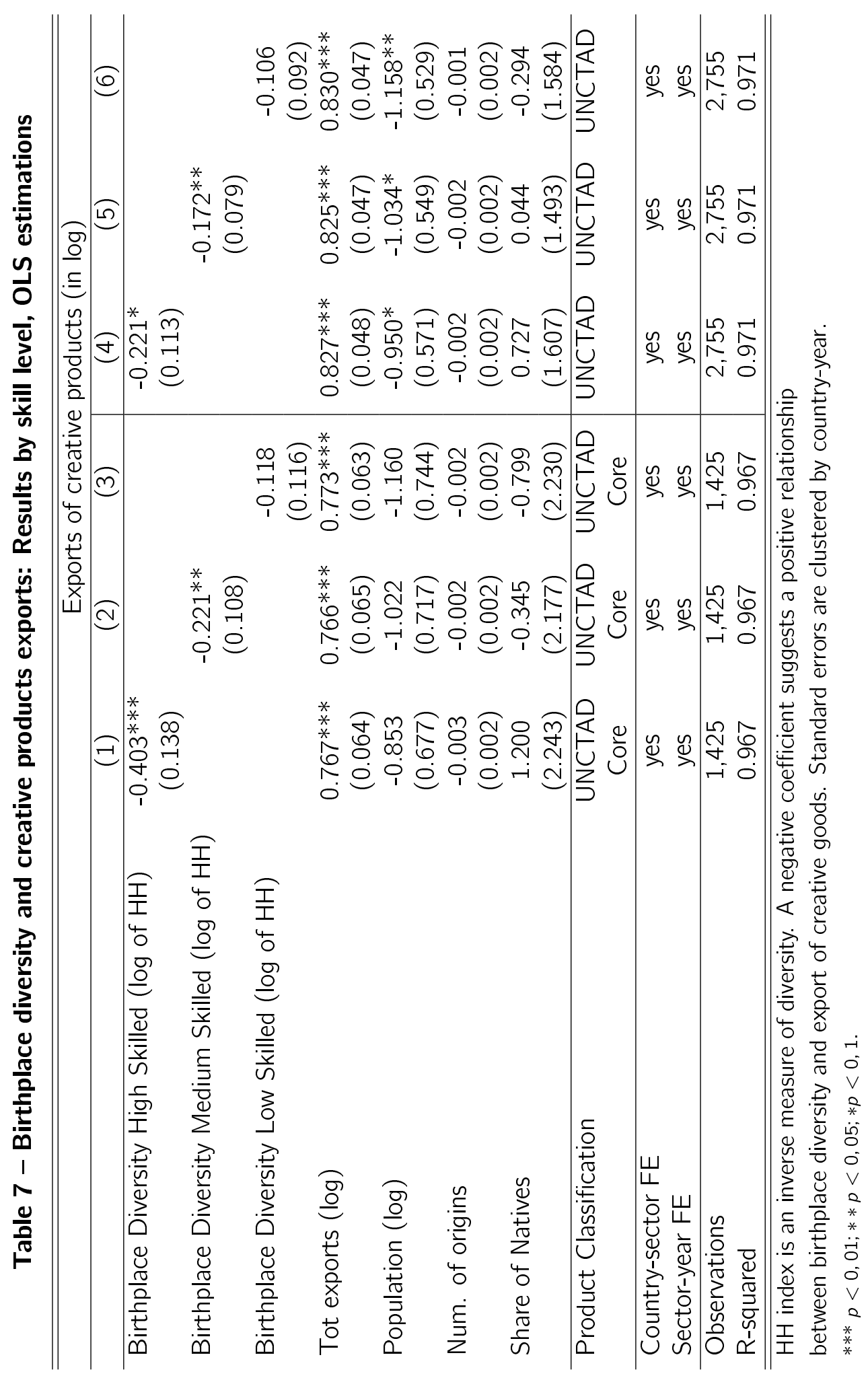


Table 8 - Birthplace diversity and creative products exports: Sector specific estimations

\begin{tabular}{lllcc}
\hline \hline Sector & Coeff & Std Err & Obs & R-sq \\
\hline Chemicals & -0.289 & $(0.475)$ & 95 & 0.912 \\
Plastic/Rubbers & $-1.110^{* * *}$ & $(0.308)$ & 95 & 0.949 \\
Wood and Wood products & $-0.914 * *$ & $(0.430)$ & 190 & 0.441 \\
Textiles & $0.510^{* * *}$ & $(0.192)$ & 190 & 0.877 \\
Stone/Glass & $-0.842 * *$ & $(0.342)$ & 285 & 0.512 \\
Metals & -0.361 & $(0.297)$ & 95 & 0.959 \\
Machinery/Electrical & -0.380 & $(0.297)$ & 95 & 0.973 \\
Miscellaneous & $-0.952^{* * *}$ & $(0.244)$ & 380 & 0.403 \\
\hline \hline
\end{tabular}

Note: Results from sector specific regressions having the log of creative exports as dependent variable and the same set of control variables as in eq. 2. Country and year fixed effects included in all regressions.

Standard errors are clustered by country.

*** $p<0,01 ; * * p<0,05 ; * p<0,1$. 


\section{Bibliography}

Abel, G. and Sander, N. (2014). Quantifying Global International Migration Flows. Science, 343(6178):1520-1522.

Alesina, A., Harnoss, J., and Rapoport, H. (2016). Birthplace diversity and economic prosperity. Journal of Economic Growth, 21(2):101-138.

Card, D. (2001). Immigrant Inflows, Native Outflows, and the Local Labor Market Impacts of Higher Immigration. Journal of Labor Economics, 19(1):22-64.

Card, D. (2009). Immigration and Inequality. American Economic Review, 99(2):1-21.

Combes, P.-P., Lafourcade, M., and Mayer, T. (2005). The trade-creating effects of business and social networks: evidence from France. Journal of International Economics, 66(1):129.

Conley, T. G., Hansen, C. B., and Rossi, P. E. (2012). Plausibly Exogenous. The Review of Economics and Statistics, 94(1):260-272.

Florida, R. (2002). Bohemia and economic geography. Journal of Economic Geography, 2(1):55-71.

Head, K. and Ries, J. (1998). Immigration and Trade Creation: Econometric Evidence from Canada. Canadian Journal of Economics, 31(1):47-62.

Herander, M. G. and Saavedra, L. A. (2005). Exports and the Structure of Immigrant-Based Networks: The Role of Geographic Proximity. The Review of Economics and Statistics, 87(2):323-335.

Hong, L. and Page, S. E. (2001). Problem Solving by Heterogeneous Agents. Journal of Economic Theory, 97(1):123-163.

Hoogendoorn, S. M. and van Praag, M. C. (2012). Ethnic Diversity and Team Performance: A Field Experiment. IZA Discussion Papers 6731, Institute for the Study of Labor (IZA).

Horwitz, S. and Horwitz, I. (2007). The effects of team diversity on team outcomes: A meta-analytic review of team demography. Journal of Management, 33(6):987-1015.

Kahane, L., Longley, N., and Simmons, R. (2013). The Effects of Coworker Heterogeneity on Firm-Level Output: Assessing the Impacts of Cultural and Language Diversity in the National Hockey League. The Review of Economics and Statistics, 95(1):302-314.

Lazear, E. P. (1999). Globalisation and the Market for Team-Mates. Economic Journal, 109(454):15-40. 
Maggi, G. and Grossman, G. M. (2000). Diversity and Trade. American Economic Review, 90(5):1255-1275.

Ottaviano, G. I. and Peri, G. (2006). The economic value of cultural diversity: evidence from US cities. Journal of Economic Geography, 6(1):9-44.

Peri, G. and Requena-Silvente, F. (2010). The trade creation effect of immigrants: evidence from the remarkable case of Spain. Canadian Journal of Economics, 43(4):1433-1459.

Peri, G. and Sparber, C. (2009). Task Specialization, Immigration, and Wages. American Economic Journal: Applied Economics, 1(3):135-169.

Rauch, J. E. (2001). Business and Social Networks in International Trade. Journal of Economic Literature, 39(4):1177-1203.

Rauch, J. E. and Trindade, V. (2002). Ethnic Chinese Networks In International Trade. The Review of Economics and Statistics, 84(1):116-130.

Silva, J. M. C. S. and Tenreyro, S. (2006). The Log of Gravity. The Review of Economics and Statistics, 88(4):641-658.

TERA (2014). The Economic Contribution of the Creative Industries to EU GDP and Employment. TERA consultants.

Trax, M., Brunow, S., and Suedekum, J. (2015). Cultural diversity and plant-level productivity. Regional Science and Urban Economics, 53(C):85-96. 


\section{A Appendix Tables}

Table A1 - Birthplace diversity and creative products exports: Augmented specification, OLS estimations

\begin{tabular}{lccc|cc}
\hline \hline & \multicolumn{5}{c}{ Exports of creative products (in log) } \\
\hline Birthplace Diversity (log of HH) & $-0.345^{* *}$ & $-0.386^{* * *}$ & $-0.387^{* * *}$ & $-0.287^{* *}$ & $-0.234^{* *}$ \\
& $(0.141)$ & $(0.134)$ & $(0.136)$ & $(0.111)$ & $(0.101)$ \\
Tot exports (log) & $0.771^{* * *}$ & $0.763^{* * *}$ & $0.763^{* * *}$ & $0.842^{* * *}$ & $0.819^{* * *}$ \\
& $(0.065)$ & $(0.066)$ & $(0.066)$ & $(0.049)$ & $(0.048)$ \\
Population (log) & -1.132 & $-1.200^{*}$ & $-1.195^{*}$ & -0.927 & $-1.306^{* *}$ \\
& $(0.713)$ & $(0.703)$ & $(0.704)$ & $(0.663)$ & $(0.600)$ \\
Per Capita GDP & -0.012 & 0.049 & 0.051 & -0.040 & 0.131 \\
& $(0.214)$ & $(0.213)$ & $(0.217)$ & $(0.188)$ & $(0.172)$ \\
Num. of origins & & -0.002 & -0.002 & $-0.002^{*}$ & -0.002 \\
& & $(0.002)$ & $(0.002)$ & $(0.001)$ & $(0.001)$ \\
Share of Natives & & & 0.107 & -1.331 & 0.498 \\
& & & $(2.142)$ & $(1.822)$ & $(1.457)$ \\
\hline Product Classification & UNESCO & UNESCO & UNESCO & UNESCO & UNCTAD \\
& Core & Core & Core & & \\
\hline Country-sector FE & yes & yes & yes & yes & yes \\
Sector-year FE & yes & yes & yes & yes & yes \\
\hline Observations & 1,425 & 1,425 & 1,425 & 1,615 & 2,755 \\
R-squared & 0.967 & 0.967 & 0.967 & 0.980 & 0.971 \\
\hline \hline
\end{tabular}

$\mathrm{HH}$ index is an inverse measure of diversity. A negative coefficient suggests a positive relationship between birthplace diversity and export of creative goods. Standard errors are clustered by country-year. $* * * p<0,01 ; * * p<0,05 ; * p<0,1$. 
Table A2 - Test of the exclusion restriction

\begin{tabular}{lccc}
\hline & \multicolumn{3}{c}{ Exports of creative products (in log) } \\
\hline & $(1)$ & $(2)$ & $(3)$ \\
\hline Birthplace Diversity (log of HH) & $-0.296^{* *}$ & -0.384 & -0.298 \\
& $(0.147)$ & $(0.283)$ & $(0.265)$ \\
Tot exports (log) & $0.767^{* * *}$ & $0.766^{* * *}$ & $0.767^{* * *}$ \\
& $(0.063)$ & $(0.065)$ & $(0.064)$ \\
Population (log) & -1.028 & -1.111 & -1.028 \\
& $(0.710)$ & $(0.699)$ & $(0.711)$ \\
Num. of origins & -0.002 & -0.002 & -0.002 \\
& $(0.002)$ & $(0.002)$ & $(0.002)$ \\
Share of Natives & -0.585 & -0.0124 & -0.588 \\
& $(2.144)$ & $(2.194)$ & $(2.257)$ \\
IV 1: BD based on imputed immigrants & -0.188 & & -0.188 \\
& $(0.199)$ & & $(0.204)$ \\
IV 2: 5-year lag BD & & -0.008 & 0.002 \\
& & $(0.252)$ & $(0.255)$ \\
\hline Country-sector FE & yes & yes & yes \\
Sector-year FE & yes & yes & yes \\
\hline Observations & 1,425 & 1,425 & 1,425 \\
R-squared & 0.967 & 0.967 & 0.967 \\
\hline \hline
\end{tabular}

$\mathrm{HH}$ index is an inverse measure of diversity. A negative coefficient suggests a positive relationship between birthplace diversity and export of creative goods.

Standard errors are clustered by country-year.

*** $p<0,01 ; * * p<0,05 ; * p<0,1$. 
Table A3 - Birthplace diversity and creative products exports: Robustness check using alternative definition of birthplace diversity, 2SLS estimations

\begin{tabular}{|c|c|c|c|}
\hline & \multicolumn{3}{|c|}{ Exports of creative products (in log) } \\
\hline & $(1)$ & $(2)$ & (3) \\
\hline \multirow[t]{2}{*}{ Birthplace Diversity $(1-\mathrm{HH})$} & $2.616^{* * *}$ & $2.007^{* * *}$ & $1.470 * *$ \\
\hline & $(0.742)$ & $(0.666)$ & $(0.616)$ \\
\hline \multirow[t]{2}{*}{ Tot exports $(\log )$} & $0.739 * * *$ & $0.816 * * *$ & $0.815 * * *$ \\
\hline & $(0.061)$ & $(0.044)$ & $(0.043)$ \\
\hline \multirow[t]{2}{*}{ Population $(\log )$} & $-2.053 * * *$ & $-1.711 * * *$ & $-1.615 * * *$ \\
\hline & $(0.708)$ & $(0.605)$ & $(0.511)$ \\
\hline \multirow[t]{2}{*}{ Num. of origins } & $-0.005 * * *$ & $-0.004 * * *$ & $-0.003 * *$ \\
\hline & $(0.001)$ & $(0.001)$ & $(0.001)$ \\
\hline \multirow[t]{2}{*}{ Share of Natives } & 0.502 & -0.789 & 0.423 \\
\hline & $(2.125)$ & $(1.789)$ & $(1.558)$ \\
\hline \multirow[t]{2}{*}{ Product Classification } & UNESCO & UNESCO & UNCTAD \\
\hline & Core & & \\
\hline Country-sector FE & yes & yes & yes \\
\hline Sector-year FE & yes & yes & yes \\
\hline IV: BD based on imputed immigrants & $0.475 * *$ & $0.477 * *$ & $0.460 * *$ \\
\hline IV: 5-year lag BD & $0.613 * * *$ & $0.612 * * *$ & $0.616 * * *$ \\
\hline F-test & 33.92 & 34.08 & 33.71 \\
\hline Hansen J & 0.427 & 0.283 & 0.035 \\
\hline Observations & 1,425 & 1,615 & 2,755 \\
\hline R-squared & 0.968 & 0.981 & 0.971 \\
\hline
\end{tabular}

Standard errors are clustered by country-year.

*** $p<0,01 ; * * p<0,05 ; * p<0,1$. 


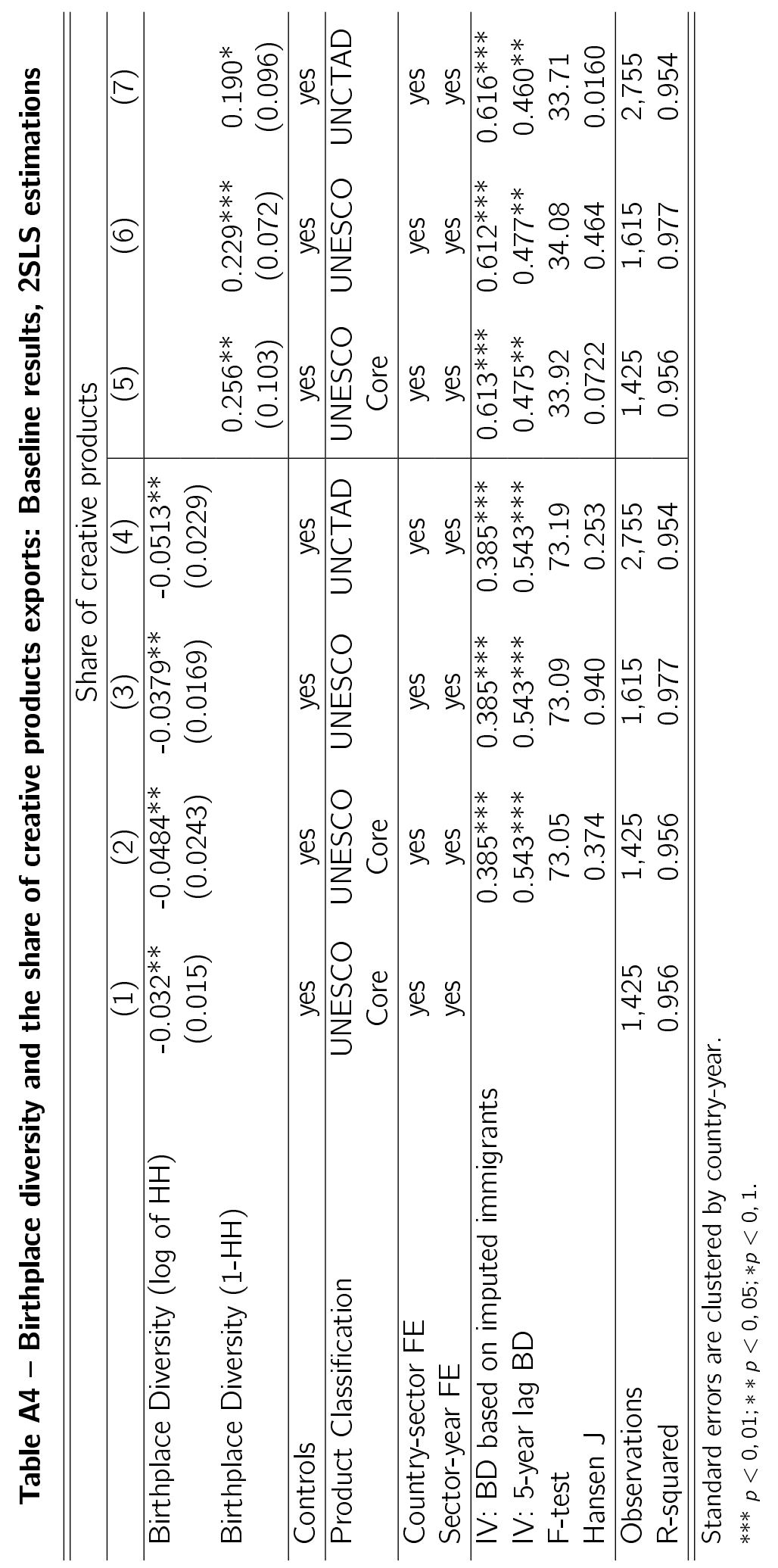




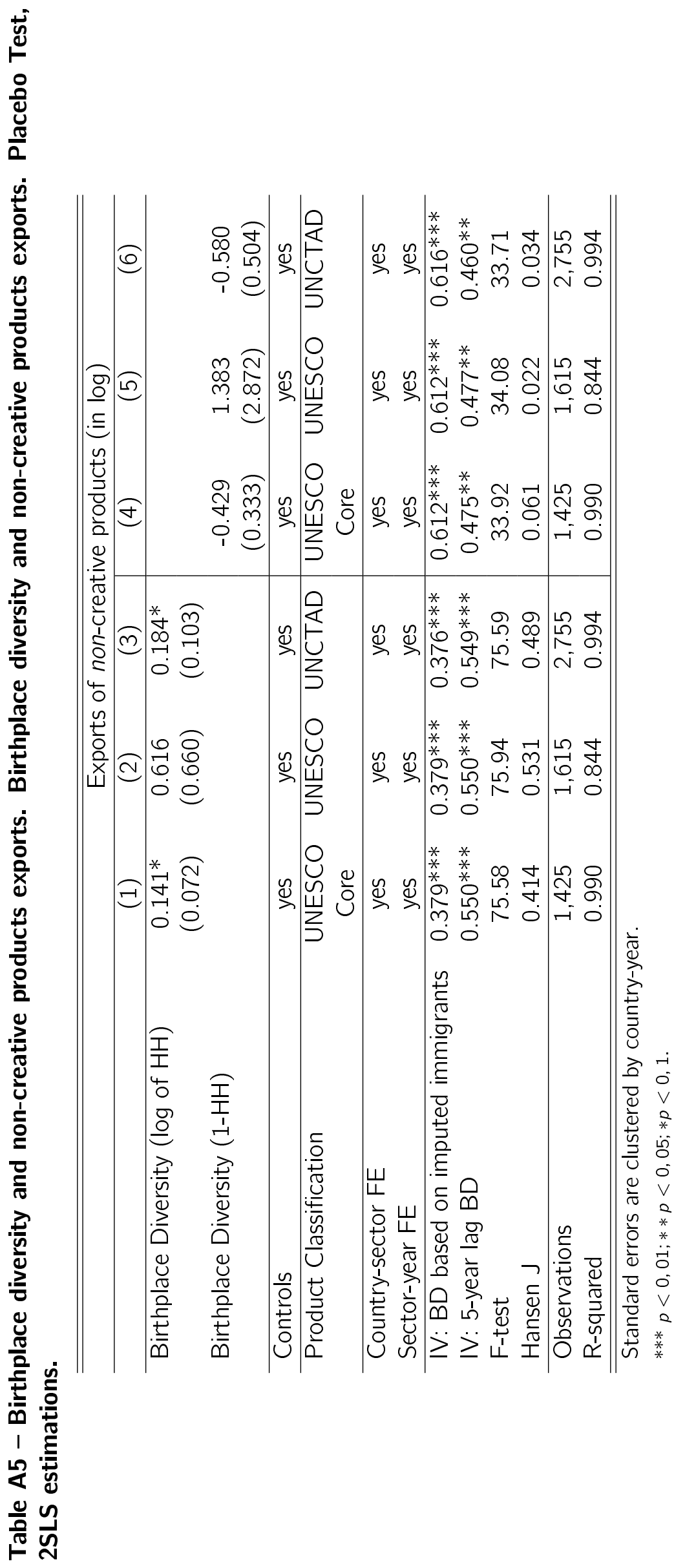

